\title{
European IPF Patient Charter: an SOS to the world
}

\author{
Bruno Crestani $i^{1,2}$
}

Affiliations: ${ }^{1}$ APHP, Hôpital Bichat, Service de Pneumologie A, Centre de Compétences des Maladies Pulmonaires Rares, Paris, France. ${ }^{2}$ Université Paris Diderot, Sorbonne Paris Cité, INSERM Unité 1152, Paris, France.

Correspondence: Bruno Crestani, Service de Pneumologie A, Hôpital Bichat, 46 rue Henri Huchard, 75877 Paris CEDEX 18, France. E-mail: bruno.crestanidaphp.fr

0

@ERSpublications

Sign the European IPF Patient Charter to help improve the status of IPF diagnosis and treatment http://ow.ly/VtoM5

This is a time of unprecedented progress in the field of respiratory medicine, particularly for idiopathic pulmonary fibrosis (IPF). In the course of one decade, the disease has been redefined, diagnostic criteria have been established [1] and the genetic mechanisms have been elucidated [2]. Two drugs have been approved (pirfenidone in 2011 in Europe and in 2014 in the USA, and nintedanib in 2014 in Europe and the USA) from results of randomised trials including thousands of patients [3-5]. Also, some previously recommended treatments, such as the combination of steroids and azathioprine, have been found deleterious [6]. We may expect further improvements with the testing of many drugs worldwide in phase 2 and 3 trials [7]. This sequence of events is quite unique in medicine, and we should be proud that pneumologists are the first specialty to have an anti-fibrotic drug approved.

However, many difficulties remain, and patients and their families are ideally placed to appreciate some of these difficulties. A recent study found that IPF patients are struggling to receive a diagnosis and are coping with a life-limiting, rapidly progressive illness, with few support structures [8]. In this issue of the European Respiratory Journal, Bonella et al. [9] present the results of interviewing patient advocacy groups regarding the care of patients with IPF in nine European countries and the charter they established after these interviews. The charter includes many proposals to improve the situation for IPF patients and could be the basis for coordinated efforts. It illuminates the current status of IPF diagnosis and treatment in the nine European countries.

The situation is not that rosy. First, the diagnosis of IPF remains difficult for many reasons, including delayed diagnosis due to insufficient awareness of the disease by general practitioners and limited expertise of many pneumologists. In the interest of patients, we need to improve how we teach the diagnosis of interstitial lung disease (ILD), targeting medical students, pneumologists and radiologists in training, and general practitioners. This education requires a coordinated effort at the local, regional, national, European and world levels. Improving the diagnostic process requires improving current diagnostic tools, such as auscultation with electronic stethoscopes or improved analysis with high-resolution computed tomography [10]. Moreover, we need to discover and validate new diagnostic tools, such as biomarkers specific for IPF or alternatives to surgical lung biopsy [11].

Secondly, access to treatment is an issue in every country, particularly in terms of pulmonary rehabilitation and lung transplantation. Although both nintedanib and pirfenidone have been approved at the European Union (EU) level, many European patients have no or limited access to these drugs. Similarly, outside Europe, many countries, accounting for thousands of IPF patients, have absolutely no access to these drugs, mostly because of their cost. Such an inequality is a problem in itself. Although financial issues cannot be ignored, a common European rule, involving patients and their representatives, should be established

Received: Nov 152015 | Accepted: Nov 172015

Conflict of interest: Disclosures can be found alongside the online version of this article at erj.ersjournals.com

Copyright @ERS 2016 
whenever possible. A similar shortage of resources contributes to the inequality of European citizens in lung transplantation. Although the new guidelines for lung transplantation establish that age by itself should not be a contraindication to lung transplantation in the absence of significant comorbidities or relative contraindications [12], many countries and many transplantation centres do not even evaluate patients older than 60 or 65 years. This is a real potential loss of opportunity because lung transplantation is the only treatment undoubtedly associated with improved survival in patients with IPF $[13,14]$.

Thirdly, the patient advocacy groups identified the need for a multidisciplinary team involved in the care of IPF patients including not only pneumologists, radiologists and pathologists but also physiotherapists and specialised nurses. The latter two categories are newcomers in the field. Indeed, although guidelines have established multidisciplinary discussion as the gold standard for the diagnosis of idiopathic interstitial pneumonia, particularly IPF $[15,16]$, the role of physiotherapists, expert nurses and psychologists was not previously promoted. Although physiotherapists are central to pulmonary rehabilitation [17], their role has not been emphasised in the care of IPF patients. Their role should be recognised and pneumologists should capitalise on a better involvement of physiotherapists in the holistic care of IPF patients. Similarly, from a patient perspective, the ILD clinical nurse specialist is an important part of the integrated care of patients. National and international respiratory societies should work to support the identification of specialised nurses in ILD clinics. The need for better psychological support is not surprising, because substantial proportions of patients with ILD show anxiety and depression (31\% and $23 \%$, respectively, in a recent study [18]). Dyspnoea and comorbidities are important disease contributors that may be amenable to intervention [18]. Genetic counselling is also a concern because up to $20 \%$ of IPF patients have evidence of familial ILD, and new genes are continually being discovered [19]. Hence, only specialised centres for ILD, organised into multidimensional networks (local, regional, national and international), will be able to put together a multidisciplinary team of such a dimension and with such a multifaceted expertise.

Fourthly, the patient advocacy groups identified a need for high-quality information about IPF at diagnosis and during follow-up: information regarding the disease itself, treatment (not limited to pharmacological treatments and specifically including palliative care) and any comorbidity. Information should be delivered by the treating pneumologist, who plays a central role as the coordinator of care. This is a new role for clinicians too. Information does exist, but access to information needs to be improved, using classical tools (paper-based) as well as modern tools (Internet-based and social network-friendly). Here again, networks of specialised centres will be most useful to improve the implementation of these tools and their dissemination.

Fifthly, the advocacy groups emphasised palliative care. Again, this is a new area, and patients are taking the lead. Poor communication and coordination of care, with little or no discussion about important end-of-life preferences, have been reported for patients with ILD, particularly IPF [20, 21]. Recent data from a phase 2 randomised controlled trial of a case conference intervention in patients with advanced fibrotic ILD and care givers identified an improvement in symptom control and quality of life [22]. Use of evidence-based guidelines and a comprehensive palliative care assessment at the case conference, ongoing palliative care involvement and/or added time with care providers may have contributed to the findings. Furthermore, these data suggest that with an early case conference, more patients are dying at home instead of in a hospital [22]. These findings support those of Higginson et al. [23], who found improvement in psychological symptoms in a recent trial of a breathlessness intervention service among 105 patients with refractory breathlessness (including patients with ILD).

Sixthly, the advocacy groups stressed the need for additional research funding. With the help of patients, expanding funding in basic, translational and clinical research in the field of IPF and other fibrotic lung diseases should be one of our objectives. IPF is a disease of ageing, and investigating and preventing lung diseases in an ageing population is one of the five major themes identified by the European Respiratory Society scientific committee as a priority for research [24]. One option might be to build an international registry for IPF [25].

The observations by the IPF patient advocacy groups are alarming and show us the unmet needs of patients. Patients are sending an SOS to physicians, funders and healthcare policymakers. The IPF Patient Charter is the right answer to this call. As of November 13, 2015, 9164 people have signed the charter. Once 35000 signatures from European citizens have been obtained, a petition can be sent to the EU Parliament. When signed by one more than $50 \%$ of the members of the EU Parliament, the IPF petition will be sent to the EU Commission in Strasbourg to stimulate immediate regulatory changes. 9164 signatures is a lot but is not enough. As physicians, we should read this charter, sign it and distribute it. So, please answer this SOS!

\section{References}

1 Raghu G, Collard HR, Egan JJ, et al. An official ATS/ERS/JRS/ALAT statement: idiopathic pulmonary fibrosis: evidence-based guidelines for diagnosis and management. Am J Respir Crit Care Med 2011; 183: 788-824.

2 Kropski JA, Blackwell TS, Loyd JE. The genetic basis of idiopathic pulmonary fibrosis. Eur Respir J 2015; 45: $1717-1727$. 
3 Noble PW, Albera C, Bradford WZ, et al. Pirfenidone in patients with idiopathic pulmonary fibrosis (CAPACITY): two randomised trials. Lancet 2011; 377: 1760-1769.

4 King TE Jr, Bradford WZ, Castro-Bernardini S, et al. A phase 3 trial of pirfenidone in patients with idiopathic pulmonary fibrosis. N Engl J Med 2014; 370: 2083-2092.

5 Richeldi L, du Bois RM, Raghu G, et al. Efficacy and safety of nintedanib in idiopathic pulmonary fibrosis. $N$ Engl J Med 2014; 370: 2071-2082.

6 Raghu G, Anstrom KJ, King TE Jr, et al. Prednisone, azathioprine, and $\mathrm{N}$-acetylcysteine for pulmonary fibrosis. N Engl J Med 2012; 366: 1968-1977.

7 Wuyts WA, Antoniou KM, Borensztajn K, et al. Combination therapy: the future of management for idiopathic pulmonary fibrosis? Lancet Respir Med 2014; 2: 933-942.

8 Duck A, Spencer LG, Bailey S, et al. Perceptions, experiences and needs of patients with idiopathic pulmonary fibrosis. J Adv Nurs 2015; 71: 1055-1065.

9 Bonella F, Wijsenbeek M, Molina-Molina M, et al. European IPF Patient Charter: unmet needs and a call to action for healthcare policymakers. Eur Respir J 2016; 47: 597-606.

10 Cottin V, Richeldi L. Neglected evidence in idiopathic pulmonary fibrosis and the importance of early diagnosis and treatment. Eur Respir Rev 2014; 23: 106-110.

11 Borensztajn K, Crestani B, Kolb M. Idiopathic pulmonary fibrosis: from epithelial injury to biomarkers - insights from the bench side. Respiration 2013; 86: 441-452.

12 Weill D, Benden C, Corris PA, et al. A consensus document for the selection of lung transplant candidates: 2014 - an update from the Pulmonary Transplantation Council of the International Society for Heart and Lung Transplantation. J Heart Lung Transplant 2015; 34: 1-15.

13 Thabut G, Christie JD, Ravaud P, et al. Survival after bilateral versus single-lung transplantation for idiopathic pulmonary fibrosis. Ann Intern Med 2009; 151: 767-774.

14 Schaffer JM, Singh SK, Reitz BA, et al. Single- $v$ s double-lung transplantation in patients with chronic obstructive pulmonary disease and idiopathic pulmonary fibrosis since the implementation of lung allocation based on medical need. JAMA 2015; 313: 936-948.

15 Raghu G. Idiopathic pulmonary fibrosis: guidelines for diagnosis and clinical management have advanced from consensus-based in 2000 to evidence-based in 2011. Eur Respir J 2011; 37: 743-746.

16 Travis WD, Costabel U, Hansell DM, et al. An official American Thoracic Society/European Respiratory Society statement: update of the international multidisciplinary classification of the idiopathic interstitial pneumonias. Am J Respir Crit Care Med 2013; 188: 733-748.

17 Wijkstra PJ, Wempe JB. New tools in pulmonary rehabilitation. Eur Respir J 2011; 38: 1468-1474.

18 Holland AE, Fiore JF Jr, Bell EC, et al. Dyspnoea and comorbidity contribute to anxiety and depression in interstitial lung disease. Respirology 2014; 19: 1215-1221.

19 Kannengiesser C, Borie R, Ménard C, et al. Heterozygous RTEL1 mutations are associated with familial pulmonary fibrosis. Eur Respir J 2015; 46: 474-485.

20 Bajwah S, Higginson IJ, Ross JR, et al. The palliative care needs for fibrotic interstitial lung disease: a qualitative study of patients, informal caregivers and health professionals. Palliat Med 2013; 27: 869-876.

21 Bajwah S, Koffman J, Higginson IJ, et al. "I wish I knew more..." the end-of-life planning and information needs for end-stage fibrotic interstitial lung disease: views of patients, carers and health professionals. BMJ Support Palliat Care 2013; 3: 84-90.

22 Bajwah S, Ross JR, Wells AU, et al. Palliative care for patients with advanced fibrotic lung disease: a randomised controlled phase II and feasibility trial of a community case conference intervention. Thorax 2015; 70: 830-839.

23 Higginson IJ, Bausewein C, Reilly CC, et al. An integrated palliative and respiratory care service for patients with advanced disease and refractory breathlessness: a randomised controlled trial. Lancet Respir Med 2014; 2: 979-987.

24 Gibson GJ, Loddenkemper R, Lundbäck B, et al. Respiratory health and disease in Europe: the new European Lung White Book. Eur Respir J 2013; 42: 559-563.

25 Ryerson CJ, Corte TJ, Collard HR, et al. A global registry for idiopathic pulmonary fibrosis: the time is now. Eur Respir J 2014; 44: 273-276. 